\title{
Flexural -Torsional Buckling Tests of Cold-Formed Lipped Channel Beams Under Restrained Boundary Conditions
}

\author{
R. KANDASAMY ${ }^{\# 1}$, R. THENMOZHI ${ }^{* 2}$, L.S.JEYAGOPAL ${ }^{\# 3}$ \\ \#1Principal - in Charge, Arulmigu Palaniandavar Polytechnic College, Palani-624601, India, \\ \#3 Mithren Structures,(Formerly Prof and Head, PSG College of Technology) Coimbatore, India. \\ 1 Email: rkandasamy65@gmail.com \\ 3 Email : proflsj@gmail.com \\ 2 Associate Professor, Government College of Technology, Coimbatore - 636002,India . \\ 2 Email : drrthenmozhigct@gmail.com
}

\begin{abstract}
In this paper, tests on flexural buckling ( Lateral - Torsional ) of cold-formed steel(CFS) lipped Channel beams under restrained boundary conditions are described Two point loading for flexural tests have been established for $3.0 \mathrm{~m}$ span to obtain uniform bending moment. The section sizes selected for testing are

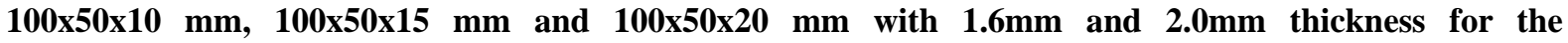
investigation. Carefully designed loading and support systems were used in the tests to apply gravity load through the web of the section and to ensure that simply supported ends were established. The test results are compared in the BS5950:Part 5 and IS code 801-1975. The influence of warping and torsional restraints on flexural capacity is presented. The influence of buckling length for different boundary conditions proposed by Rhodes was considered to calculate critical flexural-torsional buckling moment.
\end{abstract}

Keywords : - Cold-Formed Steel, Flexural torsional buckling, Finite element, Slenderness ratio, Boundary conditions and warping restraint.

\section{Introduction}

The Major advantage of CFS beams over hot rolled beams is to be found in the relative thinness of the material from which the sections are formed. This will lead to have highly effective in terms of weight and efficient member and structures. However, the promising advantages of the thin walls can only be partially obtained. To obtain these advantages, the designer must be aware of the importance associated with thin-walled members and their effects on analysis and design. The Most important of these phenomena is local buckling.

In thin walled members, the role played by torsion is enhanced in comparison to hot-rolled sections. The reasons for this are listed below

1. Application of load through the shear centre in an open cross-section which has shear centre outside the section is difficult to achieve. Hence, CFS beams are subjected to an applied torque so that twisting of the section is bound to occur if it is not restrained against torsion.

2. The torsion constant $\mathrm{J}$, for open cross sections, which is directly related to the resistance to twist, is proportional to the material thickness raised to the third power.

3. Restraining this torsion induces longitudinal stresses which may be of the same order of magnitude as the primary bending stresses and additive to them.

In most frequent applications, viz, purlins, floor joists and wall studs, the loading and restraint are both continuous, both of which are self-equilibrating to some extent so that the tendency to twist is greatly reduced. Rational methods of analysis in these situations are exceedingly complicated and design usually proceeds on the basis of test results. In this study, continuous restraint is not considered and attention is confined to cases where light gauge steel members are free to twist between discrete points of restraint.

\section{Literature Review}

Prior to 1980, the in elastic reserve capacity of beams was not included in the AISI specification because most Cold-Formed steel shapes have width to thickness ratios considerably in excess of the limits required by plastic design. In the 1970s, research work on the in elastic strength of Cold-Formed Steel beams was carried out by Reck, (1975) Pekoz, (1980) Winter (1985) and Yener (1985) at Cornell university. These studies showed that the inelastic reserve strength of Cold-Formed steel beams due to partial plasticization of the cross-section and the moment redistribution of statically indeterminate beams can be significant for certain practical shapes. With proper care, this reserve strength can be utilized to achieve more economical design of 
such members. In addition, the buckling strength and load carrying capacity of continuous of beams and steel decks have also been studied by Wang and Yeh (1974) and Chong and Mosier (1975).

Flexural capacity of discretely braced of 'C's and 'Z's was studied experimentally by Duane et al. (1992). These studies concluded that quarter point bracing is not needed for channels and Zees not attached to deck (or) sheathing. It was recommended that mid span bracing can be used to control lateral deflection and rotation at service loads. The investigation exhibited "translation rotation failure'. It should be noted that lateral buckling equations in the 1989 AISI specification for predicting the capacity were unconservative for cases where lateral braces are spaced closer than at mid point. Ultimate loads for smaller spacing of braces $(\mathrm{A} / \mathrm{L}=0.478)$ to all practical purposes were the same as for continuous bracing reported by Dr Wei Wen Yu.

Strength design curves for thin walled sections undergoing Distortional buckling were developed by Hancock et al. (1994). Two sets of design curves have been proposed and compared with test results. First set is based on an effective section approach and second one provided the prediction of Maximum stress in distortional bucking mode including post buckling reserve capacity of slender sections. Both approaches were found to produce reasonable estimation of results for sections which undergone distortional buckling before (or) at the same time as local buckling.

The behavior of edge stiffened flexural members was investigated by Maria.E. Moreya and Teoman Pekoz (1994). The experimental results showed the same trend as those of Willis and Wallace(2002). The study showed that the smallest lip size was the strongest of all the three specimen tested which was true for all brace conditions. The investigations concluded that this trend may be due to the sharing effects of lip and increase in strength was also observed.

Lateral buckling strength of cold-formed channel beams was investigated by Bogdan et al (1999). The investigation revealed that beams were failed by distortional buckling of most compressed element, quite large deformation developed as in elastic buckling loads were approached. At high half wave lengths, the mode was flexural-torsion buckling and at lower half wave lengths, the mode was lateral distortional buckling. Yield moment of CFS beams under different strain rates was studied experimentally by chi-ling and Wei-Wen Yu (2009). These studies concluded that yield moment of CFS beams increases with increasing strain rates. Experimental studies showed that dynamic yield stress (or) dynamic yield stress-strain relationship can be used in the calculation of yield moment of beams.

Lateral buckling strengths due to moment gradient effects were investigated by Cyrilus and Mahen Mahendran (2009). These studies found that strength benefit of moment gradient for cases with high end moment ratios is unfavorably influenced by Lateral Distortional buckling.

Literature study reveals that the influence of restrained boundary condition on the flexural torsional buckling resistance has not been investigated so far, particularly resistance offered by warping restraints. Various international and national codes, via, AS/NZS 4600, NAS specification, the AISI specification, Euro code and BS 5950,Part 5 have not specified the influence of warping and torsional restrains on the flexural torsional behavior. Some of the provisions appear to be based on intuition without any experimental evidence. Therefore, it is important to obtain test data for restrained CFS lipped Channel beams.

The purpose of this paper is to present a series of flexural tests on CFS lipped channel beams under restrained boundary conditions. In the past, flexural tests of thin-walled lipped channel sections with warping and torsional restraints have not been performed. Therefore, the test strengths of such sections are not known. This paper provides the test strengths of lipped channel beams. All the sections failed in lateral-torsional buckling mode where the flange and lip rotated about the flange-web junction restrained by web.

\section{Material Properties}

The material properties of each series of specimens were determined by tensile coupon tests. Longitudinal coupons were taken from the centre of the web plate of finished specimens. The coupons were prepared and tested according to Indian standard 1608:-2005 and ISO 6892:1998 for the tensile testing of metals using $20 \mathrm{~mm}$ wide coupons and gauge length $80 \mathrm{~mm}$. The coupons were tested in a $200 \mathrm{KN}$ capacity UTM using friction grips to apply loading. A data acquisition system was used to record the load and the gauge length extensions at regular intervals during the tests. The static load was obtained by pausing the applied straining for one minute near the $0.2 \%$ tensile proof stress and the ultimate tensile strength. This allowed the stress relaxation associated with plastic straining to take place. Table I summarizes the material properties determined from the coupon tests. A typical coupon test specimen used in this test program is shown in Fig. 1(a) and 1(b). The stressstrain curve for different thicknesses are shown in Fig. 2.The material properties derived from coupon test are tabulated in Table I.

\section{A. Boundary Conditions}

Beams considered for studies are simply supported and its boundary conditions for warping and torsion restraints are tabulated in Table II and shown in Fig. 3. Two 50mm x 100mm size MS plates of 3mm thick are welded, one at each end at side face of the CFS beam to introduce warping restraint fully (WR) and 50mm $\mathrm{x}$ 
50mm plates are welded to introduce partial warping restraint at ends of the beam at side face either at tension flange (WR (T)),or at compression flange (WR(C)) as shown in Fig.4.

B. Determination of Elastic Lateral Buckling Resistance Moment $\left(M_{b}\right)$

In BS 5950: Part 5, the rules for determination of the elastic lateral buckling resistance are limited to four specified sections, such as I, C, Z and T beams as shown in Fig.5. These thin elements may buckle locally at a stress level lower than the yield stress of steel when they are subject to compression in flexural bending, axial compression, shear or bearing. The coefficient $C_{b}$ is used to take account of the variation in moment along a beam. The variation of $\mathrm{C}_{\mathrm{b}}$ factor with distribution of moment over the span.

C. Experimental Program : Support System and Loading

In order to investigate the Flexural - Torsional Buckling (Lateral - Torsional buckling ) and ultimate strength behavior of CFS lipped channel beams used as flexural members, a full scale bending test rig was designed, fabricated and built in the GCT structural dynamics Engineering Laboratory. The test rig used for lateral distortional buckling tests included a support system and a loading system, in which support system were rigidly fixed in the floor of dynamics laboratory.

Mahendran and Doam (1999) used a loading system with hydraulic jacks. There was a disadvantage of restraining lateral movement of the test beam. It did not allow the continuation of loading into the post buckling range due to the fact that roller bearings could slip out of position and cause injuries to people and damage the components. To eliminate the above mentioned short comings, a new gravity loading system was designed with two rectangular box shaped arrangements suspended from the attachments fixed at $1 / 3^{\text {rd }}$ points of the test beams attached with chains to accommodate leading discs. It ensured uniform bending moment between the loading points. Zhao et al (1995) and Mahendran and Doam (1999) used the overhang loading method to investigate the lateral buckling of simply supported beams. In this method, the cantilever loads are applied to the test beam at a short distance from the supports. It also provides a uniform bending moment within the entire span. So this method is preferred but it has an undesirable effect of warping restraints due to the overhang component of the test beam. Also it has the limitation on its length due to fabrication difficulties. Hence, longer test beam to accommodate cantilever loads is not suitable in this method and also in this test program. Put et al (1999) used quarter point loading method to investigate the lateral buckling method to investigate the lateral buckling of simply supported beams. This method provides uniform bending moment only between the points of load application. Due to this reason, Overhang loading method was preferred as it provides a uniform bending moment within the entire span, but it has the possible undesirable effect of warping restraints due to the overhang component of the test beam. In addition, it has the limitation on its length due to fabrication difficulties. Hence, longer test beam to accommodate cantilever loads in the overhang method was not suitable in this test program. Therefore two point loading method was adopted as shown in Fig.6(a).

Two Specially designed supports of $1.2 \mathrm{~m}$ high were fabricated and installed at a spacing of 3 meter in the floor of dynamics Laboratory to support the test beams. The height of the support was fixed in order to provide space for loading platform which will be attached to the beam so that loading will be done incrementally. The two Tshaped torsion restraint plates were fixed by using four bolts at the ends of the beam to provide torsional restraint at support. Fig.7 shows the schematic and overall views of the measuring system.

The detailed test configuration of the flexural tests is shown in Fig.10 for 100mm deep section. The two point bending arrangement provided a central region of uniform bending moment and Zero shear force. The channel section members were loaded symmetrically at two points via two box hanging arrangements. The distance between the two box arrangements was $1000 \mathrm{~mm}$. The two box hanging arrangements ensured that the applied loads are vertical. Two dial gauges were used to measure lateral deflection (Out of plane deflection) at mid span and one third span respectively. Two scales were mounted on a separate horizontal beam to measure vertical deflection at mid span and one third span which was placed just above the top of beam. This arrangement is suitable to measure vertical movement of the beam during testing without any disturbance. Rotation of the beam during the tests is recorded by mounting horizontal bar via two vertical plates fixed at the centre of beam. Vertical deflections were measured by affixing a needle at $1 / 3^{\text {rd }}$ and mid span points which moves on a reference scale. Lateral movements of beam were measured by mounting dial gauges on a stand $1 / 3^{\text {rd }}$ and mid span respectively. Strain readings were recorded with the help of strain indicator.

D. Test Procedure.

Table III lists the test specimens used in this program while Fig.10(a) shows a typical specimen arrangement for testing. The cross section dimensions and material thicknesses of each test specimen were measured using a vernier caliper and tabulated. The test specimen was placed in a position on Supports and its ends were tied down with ' $T$ ' plates which were fixed at beam ends. The loading arms were then bolted to the test specimen at each $1 / 3^{\text {rd }}$ points. The loading boxes were hanged from the loading arms by of chains. Initial deflections and strains were measured for loading box of weight $400 \mathrm{~N}$.Gravity loads of $200 \mathrm{~N}, 100 \mathrm{~N}$ and $50 \mathrm{~N}$ were purchased specifically for this test. The beam was tested by applying load at an increment of $200 \mathrm{~N}$ till the test specimen was failed and corresponding deflections and strains were recorded. The Cross-Sectional rotation of specimen was measured at 1/3rd span and corresponding rotations at mid span were extra-polated. The beam 
was allowed to deflect and rotate laterally until it was failed by out-of-plane buckling. The buckling behavior of the test beam shown in Fig.12 was observed throughout the test and recorded. Loading pattern was demonstrated in Fig 9 (a) and the pattern of failure was shown in Fig. 10(b).

\section{Results and Discussion}

Critical behavior of CFS lipped channel beams under restrained boundary conditions for member length of 3.0 $\mathrm{m}$ is presented. It is observed for class A (torsionally restrained) beams from the experimental study that the flexural capacity increases by $11.11 \%$ for the increase of lip size from $10 \mathrm{~mm}$ to $15 \mathrm{~mm}$ with $1.6 \mathrm{~mm}$ thickness. It increases by $6.67 \%$ for the increase of lip size from $15 \mathrm{~mm}$ to $20 \mathrm{~mm}$ with $2.0 \mathrm{~mm}$ thickness as shown in Fig.11(a) and 11(b). Also, it is observed for class B (warping and torsionally restrained) beams that flexural capacity increases by $5.71 \%$ for the increase of lip size from $10 \mathrm{~mm}$ to $15 \mathrm{~mm}$ with $1.6 \mathrm{~mm}$ thickness, $4.55 \%$ for the increases lip size from $15 \mathrm{~mm}$ to $20 \mathrm{~mm}$ with $2.0 \mathrm{~mm}$ thickness. Further, it is inferred for class $\mathrm{C}$ beams that flexural capacity increases by $9.09 \%$ for the increase of lip size from $10 \mathrm{~mm}$ to $15 \mathrm{~mm}$ with $1.6 \mathrm{~mm}$ thickness, and increases by $7.69 \%$ for the increase of lip size from $15 \mathrm{~mm}$ to $20 \mathrm{~mm}$ with $2.0 \mathrm{~mm}$ thickness. Also it is inferred for class D beams that flexural capacity increases by $9.68 \%$ for the increase of lip size from $10 \mathrm{~mm}$ to $15 \mathrm{~mm}$ with $1.6 \mathrm{~mm}$ thickness, and increases by $8.82 \%$ for the increase of lip size from $15 \mathrm{~mm}$ to $20 \mathrm{~mm}$ with $2.0 \mathrm{~mm}$ thickness. Hence, it is concluded that flexural capacity increases substantially when lip size increases from $10 \mathrm{~mm}$ to $15 \mathrm{~mm}$ than from $15 \mathrm{~mm}$ to $20 \mathrm{~mm}$.It is established from the experimental study that warping restraint in addition to torsional restraint increases the flexural capacity by $29.6 \%$ for $10 \mathrm{~mm}$ lip size, $23.33 \%$ for $15 \mathrm{~mm}$ lip size for the CFS beam of $1.6 \mathrm{~mm}$ thickness. Also, it is found that warping restraint in addition to torsional restraint for $2.0 \mathrm{~mm}$ thick CFS beam increases the flexural capacity by $46.67 \%$ for $15 \mathrm{~mm}$ lip size and by $43.75 \%$ for $20 \mathrm{~mm}$ lip size. It is determined from the study that warping restraint provided to compression flange in addition to torsional restraint increases the flexural capacity for $1.6 \mathrm{~mm}$ thick CFS beam by $22.2 \%$ for $10 \mathrm{~mm}$ lip size and $20 \%$ for $15 \mathrm{~mm}$ lip size. Also, it is found that partial restraint to warping in addition to torsional restraint influences the flexural capacity by $44.4 \%$ increase for $15 \mathrm{~mm}$ lip size and $40 \%$ increase for $20 \mathrm{~mm}$ lip size for the same thickness of $2.0 \mathrm{~mm}$. Further, It is observed that warping restraint to tension flange in addition to torsional restraint for $1.6 \mathrm{~mm}$ thick CFS beam increases the flexural capacity by $14.81 \%$ for $10 \mathrm{~mm}$ lip size and by $13.33 \%$ for $15 \mathrm{~mm}$ lip size. Also, it is found that partial restraint to warping tension in addition to torsional restraint influences the flexural capacity of CFS beam by $25.9 \%$ increase for $15 \mathrm{~mm}$ lip size and by $23.33 \%$ for $20 \mathrm{~mm}$ lip size for the same thickness of $2.0 \mathrm{~mm}$.It is observed from the experimental study that partial restraint to warping provided to compression flange influences greatly on the flexural capacity of CFS beams than warping restraint provided to tension flange. Also it is found that flexural capacity of both warping and torsionally restrained CFS beam decreases when lip size increases by $6.3 \%$ for $10 \mathrm{~mm}$ to $15 \mathrm{~mm}$, by $2.9 \%$ for $15 \mathrm{~mm}$ to $20 \mathrm{~mm}$. Test results are compared with the results obtained from BS 5950, Part 5 in Table IV. The close agreement between the two moments thus verified the accuracy of gravity load readings. The mean value of the ratio of experiment to predicted results $\left(\mathrm{M}_{\mathrm{Ltb}} / \mathrm{M}_{\mathrm{b}}\right)$ is 1.03 for torsionally restrained beams, 1.065 for warping and torsionally restrained beams, 1.13 for warping (compression flange only) and torsionally restrained beams and 1.097 for warping (Tension flange only) and torsionally restrained beams.

A. Vertical Deflection Curves

The experimental curves of applied moment versus vertical deflection and lateral deflection at mid span and $1 / 3^{\text {rd }}$ span of test beams were presented. From these figures, it could be seen that the moment Vs vertical and lateral deflection curves were non-linear. However, there was a linear relationship in moment Vs vertical deflection up to $80 \%$ of the ultimate moment. For moment Vs lateral deflections, there was a linear behavior in the beginning stage: The lateral buckling tests of CFS beams by Bogdan et.al (1999) and ColdFormed RHS beams presented by Zhao et al (1995) had shown similar relationships between the applied moment and deflections. From Fig.10, it can be noticed that the sections with different slenderness have different in-plane and out-of-plane stiffness. It was measured that the maximum in plane deflection was achieved with the beam sections having less slenderness values whereas the maximum out of plane deflection was achieved with the more slender beam sections. This development was realized as the less slender beams can resistant larger moments than the more slender beams before it fails by lateral distorsional buckling (i.e. out of plane buckling). This could be due to certain experimental errors. By comparing the load-deflection behavior of less slender beams with more slender beams, less slender beams clearly demonstrate a peak load and load drop off in their corresponding graphs. 


\section{Conclusions}

The flexural-buckling (Lateral-torsional) tests on CFS lipped channel beams for different boundary conditions were conducted in a purpose-built test rig. The support and loading systems were specially designed to satisfy the idealized boundary conditions required for such flexural buckling tests. The tests included 12 different section geometries, giving a total of 16 flexural buckling tests. The non-linear behavior of CFS lipped channel beams with defined boundary conditions was discussed using moment versus deflection and longitudinal strains for various sections. The influence of warping and torsional restraint on the flexural capacity of the CFS beams was also presented and discussed. The flexural buckling test results were compared with the predictions of member capacities calculated using BS 5950 Part 5 British Code and IS code 801-1975. The test results were in good agreement with the results derived using BS 5950-Part 5.

- Warping and Torsional restraint provided at the supports increases the flexural capacity substantially to a greater extent.

- Warping restraint provided to the compression flange has more influence on the flexural capacity than warping restraint provided to tension flange

It is concluded from the experimental study that lip size of $15 \mathrm{~mm}$ and $2.0 \mathrm{~mm}$ thickness will be the optimum size considering flexural-torsional buckling of CFS beams under restrained boundary conditions. Due to warping restraint, CFS beams have more flexural capacity( i.e. $46.67 \%$ ) than torsionally restrained beams under restrained boundary conditions. All the results would then be used to develop accurate design rules for CFS lipped channel beams under restrained boundary conditions subjected to flexural bending.

\section{Acknowledgement}

The author greatly acknowledges the contribution of Dr L.S.Jeyagopal, Chairman , Mithren Structures, Coimbatore for his novel of idea of setting up of Test Setup to this project. The continuous encouragement of my supervisor Dr R. Thenmozhi is highly appreciable. The author highly indebted to the Management, particularly the then Principal of Arulmigu Palaniandavar Polytechnic college for the permission and sanctioning of funds for the project to carry out the experimental study.

\section{References}

[1] Bogdan, M. Put, Yong-Lin Pi, and. Trahair N.S (1999), “Lateral Buckling Tests on Cold-Formed Channel Beams, “ Journal of Structural Division, ASCE, Vol. 125, No. 5, pp 532 - 539.

[2] Chi-Ling Pan, and Wei-Wen Yu (2001), "Yield moment of cold-formed steel beams under different strain rates, "Journal of Structural Engineering, Vol.127, No.3, pp264-270.

[3] Chong, K.P., and D.M. Mosier (1975) "Non linear behavior of continuous cold-formed beams" Proceedings of the $3^{\text {rd }}$ international specialty conference on cold-formed steel structures, W.W.Yu and J.H. Senne Eds, University of Missouri-Rolla, pp 227-250.

[4] Cyrilus, W.K, and Mahen Mahendran (2009),"Lateral buckling strength of simply supported lite steel beams subject to moment gradient effects, "Journal of Structural Engineering,Vol.135, No.9, pp 1058-1066.

[5] Hancock. G.J.,.Kwon. Y.B, and. Stephen Bemard E (1994), "Strength design curves for thin-walled sections undergoing distortional buckling”, Journal of Constructional steel and Research, Vol.31(2-3), pp 169-186.

[6] Maria. E. Moreya and Pekoz T. (1994), “Experiments on lipped channel flexural members”, Proceeding of $12^{\text {th }}$ international specialty conference on cold-formed steel structures, St. Louis, Missouri, USA Oct 18-19, pp 41-56.

[7] Paul Bezkorovainy, Tim Burns and Kim Rasmussen J. R. (2003), "Strength curves for metals plates in compression”, Journal of Structural Engineering, ASCE, 129 (11), Vol pp 1433-1440.

[8] Reck, H.P.,.Pekoz T, and.Winter G (1975), “ Inelastic strength of cold-formed steel beams” Journal of the Structural Division, ASCE Proceedings, Vol.101, No. 11, pp2193 - 2203

[9] Rhodes, J" Design of Cold Formed Steel Members ", Elsevier Applied Science, London and New York.

[10] Wang, S.T., and Yeh S.S. (1974), “ Post-local buckling behavior of continuous beams,” Journal of the Structural Division, ASCE Proceedings, Vol.100, pp 1178-1187.

[11] Wei-Wen Yu, and Roger LaBoube, “Cold-Formed Steel Design”, Fourth Edition, WILEY, John Wiley \& Sons, Inc.

[12] Yener, M., and Pekoz T. (1980), “Inelastic load carrying capacity of Cold-Formed Steel Beams,”. Proceedings of the $5^{\text {th }}$ international speciality conference on Cold-Formed Structures, W.W. Yu and J.H. Senne, Eds., University of Missouri-Rolla, pp $145-174$.

[13] Yener, M., and Pekoz T. (1985), "Partial stress redistribution in cold-formed steel, "Journal of structural Engineering, ASCE, Vol.111, No.6, pp 1169-1186.

[14] Yener, M., and Pekoz T. (1985), “ Partial moment redistribution in cold-formed steel, “ Journal of Structural Engineering, Vol.111, No.6, pp 1187-1203.

[15] Zhao, X.L., Hancock. G.J., and. Trahair N.S (1995), "Lateral buckling tests of cold-formed RHS beams”, Journal of Structural Engineering, ASCE, Vol.121, No.11,pp 1656-1673. 


\section{Notations}

The following symbols are used in this paper.

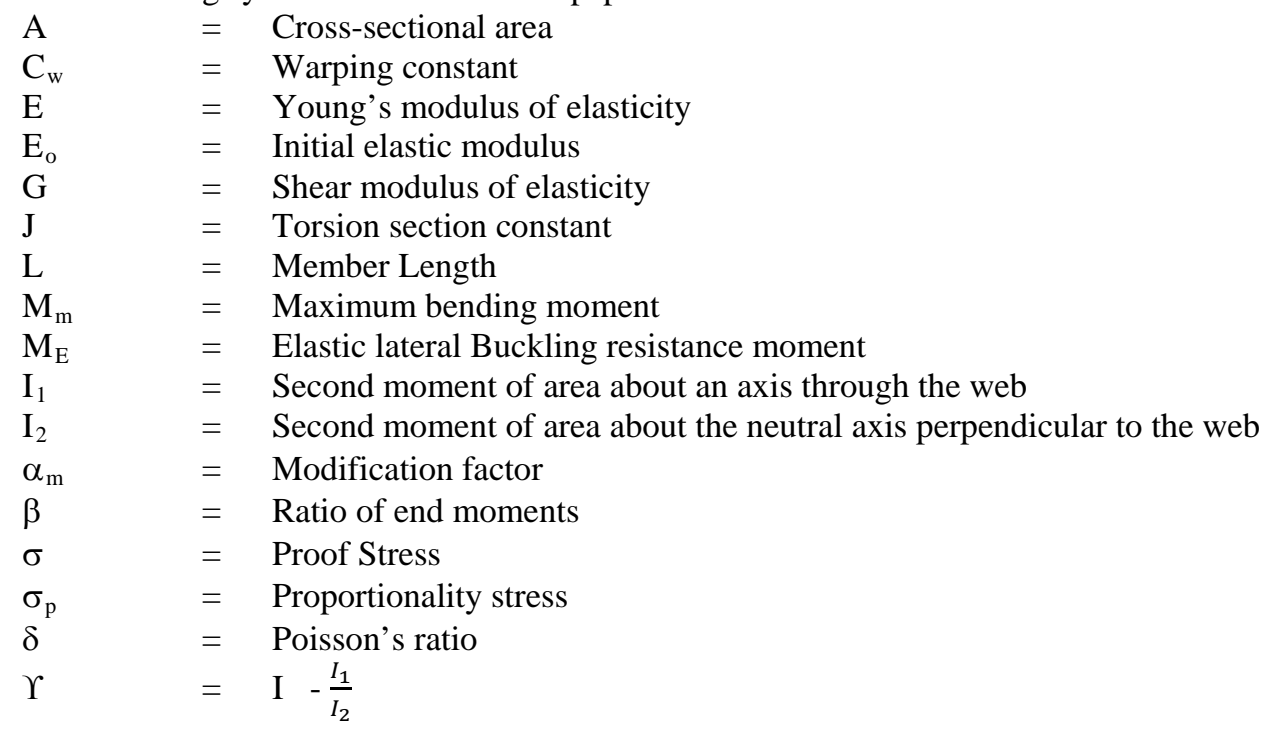

Table I. Nominal and Measured Properties

\begin{tabular}{|l|l|l|l|l|l|}
\hline \multirow{2}{*}{ Test Series } & \multirow{2}{*}{$\begin{array}{l}\text { Nominal } \\
\boldsymbol{\sigma}_{\mathbf{0 . 2}}(\mathbf{M P a})\end{array}$} & \multicolumn{2}{|l|}{ Measured } & \\
\cline { 3 - 6 } & 400 & $\boldsymbol{\sigma}_{\mathbf{0 . 2}}(\mathbf{M P a})$ & $\boldsymbol{\sigma}_{\mathbf{u}}(\mathbf{M P a})$ & $\mathbf{E}(\mathbf{M P a})$ & $\boldsymbol{\varepsilon}_{\mathbf{u}} \%$ \\
\hline CFS 1.6 & 428 & 478 & $2.01 \times 10^{5}$ & 13.8 \\
\hline CFS 2.0 & 400 & 402 & 492 & $2.01 \times 10^{5}$ & 12.9 \\
\hline CFS 2.5 & 400 & 431 & 565 & $2.01 \times 10^{5}$ & 14.8 \\
\hline CFS 3.0 & 400 & 408 & 463 & $2.01 \times 10^{5}$ & 13.4 \\
\hline
\end{tabular}

Table II. Boundary Conditions at Supports

\begin{tabular}{|l|l|l|l|}
\hline \multirow{2}{*}{ Sl.No. } & \multirow{2}{*}{ Type } & \multicolumn{2}{|l|}{ Conditions of Restraint at supports } \\
\cline { 3 - 4 } & & Torsion Restraint $*$ & Warping Restraint $* *$ \\
\hline 1 & Class A & Fully restrained & Warping not restrained in both flange(WF) \\
\hline 2 & Class B & Fully restrained & Both flanges fully restrained ( WR ) \\
\hline 3 & Class C & Fully restrained & Compression Flanges Fully Restrained (WR(c)) \\
\hline 4 & Class D & Fully restrained & Tension Flanges Fully Restrained(WR(T)) \\
\hline
\end{tabular}

* Torsion restraint prevents rotation about the longitudinal axis

** Warping restraint prevents rotation of the Flange in its Plane. 
Table III. Specimen Details.

\begin{tabular}{|l|l|l|l|l|l|l|l|}
\hline $\begin{array}{l}\text { SL. } \\
\text { NO }\end{array}$ & Specimen id & Size(mm) & Thickness & $\mathrm{D} / \mathrm{t}$ & $\mathrm{B} / \mathrm{t}$ & $\mathrm{d} / \mathrm{t}$ & Boundary conditions \\
\hline 1 & Aw.N.11 & $100 \times 50 \times 10$ & 1.6 & 62.5 & 31.3 & 6.3 & WFTR \\
\hline 2 & Aw.F.11 & $100 \times 50 \times 10$ & 1.6 & 62.5 & 31.3 & 6.3 & WRTR \\
\hline 3 & Aw.T.11 & $100 \times 50 \times 10$ & 1.6 & 62.5 & 31.3 & 6.3 & WR@TR \\
\hline 4 & Aw.B.11 & $100 \times 50 \times 10$ & 1.6 & 62.5 & 31.3 & 6.3 & WR(T)TR \\
\hline 5 & Aw.N.21 & $100 \times 50 \times 15$ & 1.6 & 62.5 & 31.3 & 9.4 & WFTR \\
\hline 6 & Aw.F.21 & $100 \times 50 \times 15$ & 1.6 & 62.5 & 31.3 & 9.4 & WRTR \\
\hline 7 & Aw.T.21 & $100 \times 50 \times 15$ & 1.6 & 62.5 & 31.3 & 9.4 & WR@TR \\
\hline 8 & Aw.B.21 & $100 \times 50 \times 15$ & 1.6 & 62.5 & 31.3 & 9.4 & WR(T)TR \\
\hline 9 & Aw.N.22 & $100 \times 50 \times 15$ & 2.0 & 50.0 & 25.0 & 7.5 & WFTR \\
\hline 10 & Aw.F.22 & $100 \times 50 \times 15$ & 2.0 & 50.0 & 25.0 & 7.5 & WRTR \\
\hline 11 & Aw.T.22 & $100 \times 50 \times 15$ & 2.0 & 50.0 & 25.0 & 7.5 & WRCTR \\
\hline 12 & Aw.B.22 & $100 \times 50 \times 15$ & 2.0 & 50.0 & 25.0 & 7.5 & WR(T)TR \\
\hline 13 & Aw.N.32 & $100 \times 50 \times 20$ & 2.0 & 50.0 & 25.0 & 10.0 & WFTR \\
\hline 14 & Aw.F.32 & $100 \times 50 \times 20$ & 2.0 & 50.0 & 25.0 & 10.0 & WRTR \\
\hline 15 & Aw.T.32 & $100 \times 50 \times 20$ & 2.0 & 50.0 & 25.0 & 10.0 & WR@TR \\
\hline 16 & Aw.B.32 & $100 \times 50 \times 20$ & 2.0 & 50.0 & 25.0 & 10.0 & WR(T)TR \\
\hline
\end{tabular}

\footnotetext{
* WFTR - Warping Free and Torsion Restrained

* WRTR - Torsion Restrained and Warping Restrained Fully

* WR@TR - Torsion Restrained and Warping Restrained at Topside

* WR(T)TR - Torsion Restrained and warping Restrained at Bottom side
}

Table IV. Comparison of Test results and Code Predictions

\begin{tabular}{|c|c|c|c|c|c|c|c|c|c|}
\hline $\begin{array}{l}\text { Sl. } \\
\text { No }\end{array}$ & $\begin{array}{l}\text { Specimen } \\
\text { id }\end{array}$ & $\begin{array}{l}\text { Thick } \\
\text { ness } \\
\text { (mm) }\end{array}$ & $\begin{array}{l}\text { Exp.v } \\
\text { alues } \\
\mathbf{M}_{\mathrm{Ltb}} \\
(\mathrm{KNm})\end{array}$ & $\begin{array}{l}\text { Buckling } \\
\text { moment } \\
\mathbf{M}_{\mathrm{b}(\mathrm{KNm})} \\
\text { (Theoretic } \\
\text { al as per } \\
\text { BS 5950- } \\
\text { Part V) }\end{array}$ & $\begin{array}{c}\text { Lateral } \\
\text { Buckling } \\
\text { Moment } \\
\text { As per Is } \\
\text { code 801- } \\
1995 \mathrm{M}_{\mathrm{LB}} \\
\mathrm{KNm}\end{array}$ & $\begin{array}{c}\text { Ratio } \\
\mathbf{M}_{\mathbf{L t b}} / \mathbf{M}_{\mathbf{L B}}\end{array}$ & $\begin{array}{l}\text { Lateral } \\
\text { Buckling } \\
\text { Moment } \\
\text { As per from } \\
\text { Finite Element } \\
\text { Analysis } M_{\text {FEA }}\end{array}$ & $\begin{array}{l}\text { Rati } \\
\mathbf{o} \\
\mathbf{M}_{\text {Ltb }} \\
/ \mathbf{M}_{\mathbf{b}}\end{array}$ & $\begin{array}{l}\text { Ratio } \\
\mathbf{M}_{\text {Ltb }} / \\
\mathbf{M}_{\text {FEA }}\end{array}$ \\
\hline 1 & Aw.N.11 & 1.6 & 2.7 & 2.36 & 1.95 & 1.38 & 2.623 & 1.14 & 2.30 \\
\hline 2 & Aw.F.11 & 1.6 & 3.5 & 3.22 & 2.37 & 1.48 & 3.549 & 1.08 & 3.28 \\
\hline 3 & Aw.T.11 & 1.6 & 3.3 & 2.76 & 2.31 & 1.42 & 3.316 & 1.19 & 2.78 \\
\hline 4 & Aw.B.11 & 1.6 & 3.1 & 2.55 & 2.29 & 1.35 & 3.086 & 1.21 & 2.55 \\
\hline 5 & Aw.N.21 & 1.6 & 3 & 2.59 & 2.20 & 1.36 & 2.964 & 1.15 & 2.57 \\
\hline 6 & Aw.F.21 & 1.6 & 3.7 & 3.42 & 2.65 & 1.68 & 3.742 & 1.08 & 3.46 \\
\hline 7 & Aw.T.21 & 1.6 & 3.6 & 2.99 & 2.59 & 1.39 & 3.621 & 1.20 & 3.01 \\
\hline 8 & Aw.B.21 & 1.6 & 3.4 & 2.79 & 2.56 & 1.32 & 3.393 & 1.21 & 2.80 \\
\hline 9 & Aw.N.22 & 2 & 3 & 3.24 & 2.66 & 1.13 & 3.111 & 0.92 & 3.38 \\
\hline 10 & Aw.F.22 & 2 & 4.4 & 4.2 & 3.20 & 1.38 & 4.463 & 1.04 & 4.29 \\
\hline 11 & Aw.T.22 & 2 & 3.9 & 3.71 & 3.12 & 1.25 & 4.005 & 1.05 & 3.81 \\
\hline 12 & Aw.B.22 & 2 & 3.4 & 3.47 & 3.09 & 1.10 & 3.421 & 0.97 & 3.52 \\
\hline 13 & Aw.N.32 & 2 & 3.2 & 3.46 & 2.88 & 1.07 & 3.263 & 0.92 & 3.54 \\
\hline 14 & Aw.F.32 & 2 & 4.6 & 4.36 & 3.42 & 1.35 & 4.688 & 1.06 & 4.42 \\
\hline 15 & Aw.T.32 & 2 & 4.2 & 3.91 & 3.34 & 1.26 & 4.290 & 1.07 & 4.00 \\
\hline 16 & Aw.B.32 & 2 & 3.7 & 3.68 & 3.31 & 1.12 & 3.812 & 1.00 & 3.81 \\
\hline
\end{tabular}




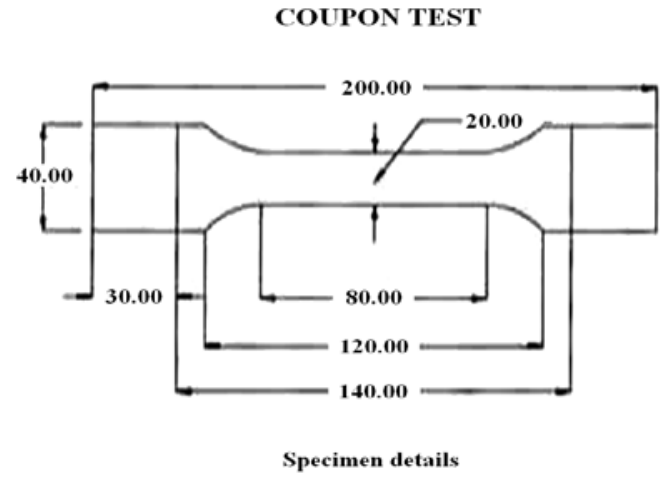

Fig. 1(a). Specimen

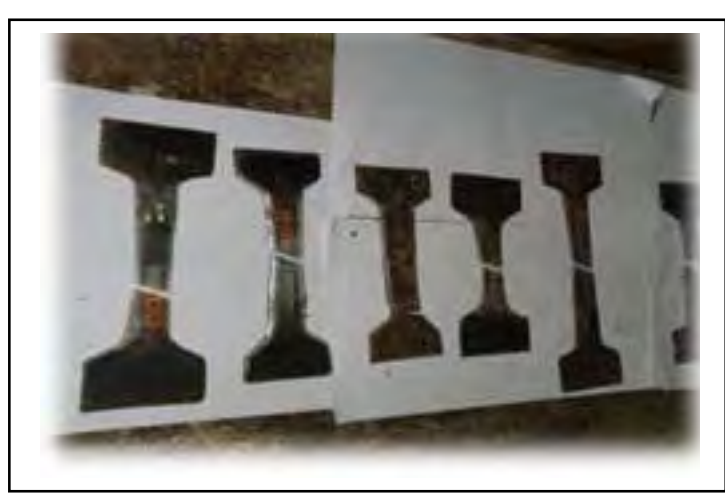

Fig.1(b). Failure Pattern

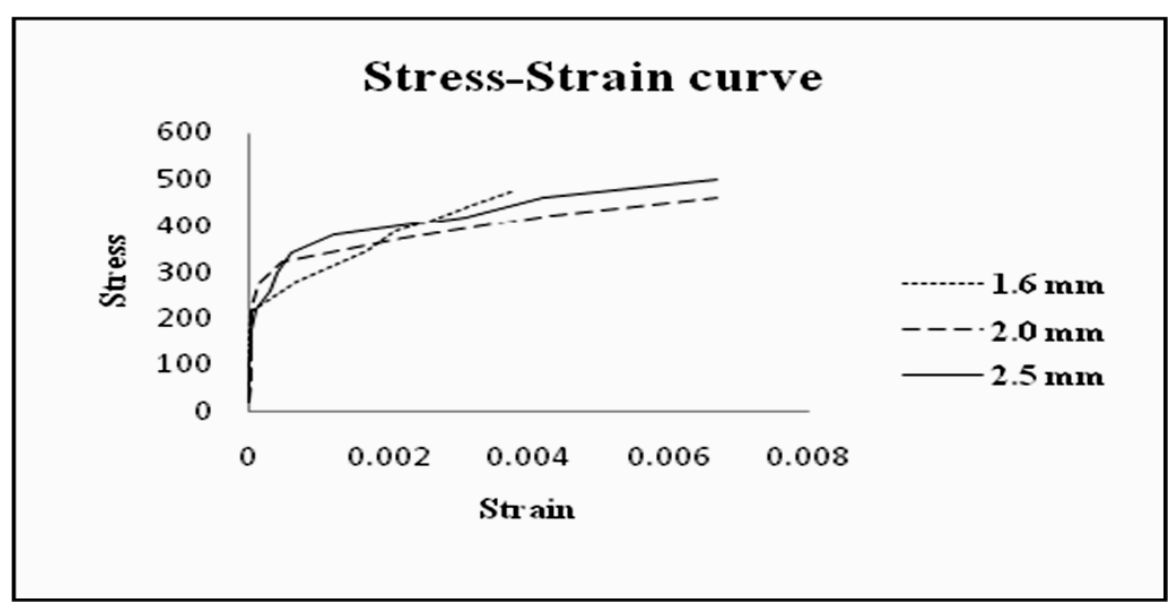

Fig.2. Stress-Strain Curve

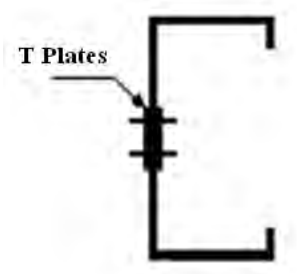

(a)

Torsional restraint

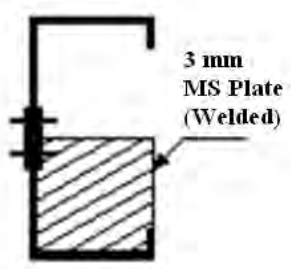

(b)

Warping

restraint at

bottom side

(Tension Flange)

and Torsional

restraint

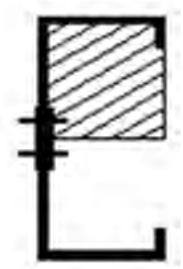

(c)

Warping

restraint

Top side

(Comp.Flange)

and Torsional

restraint

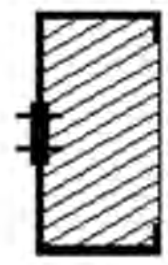

(d)

Warping restraint and Torsional restraint

Fig.3. Boundary Conditions
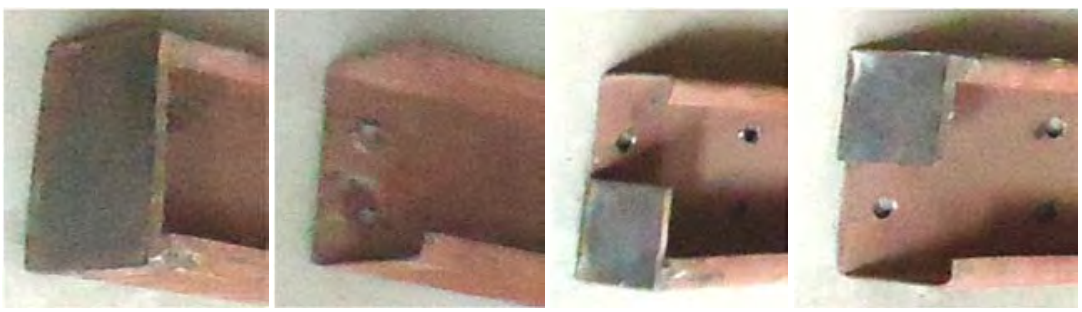

Fig.4. Four Boundary Conditions (Warping) 


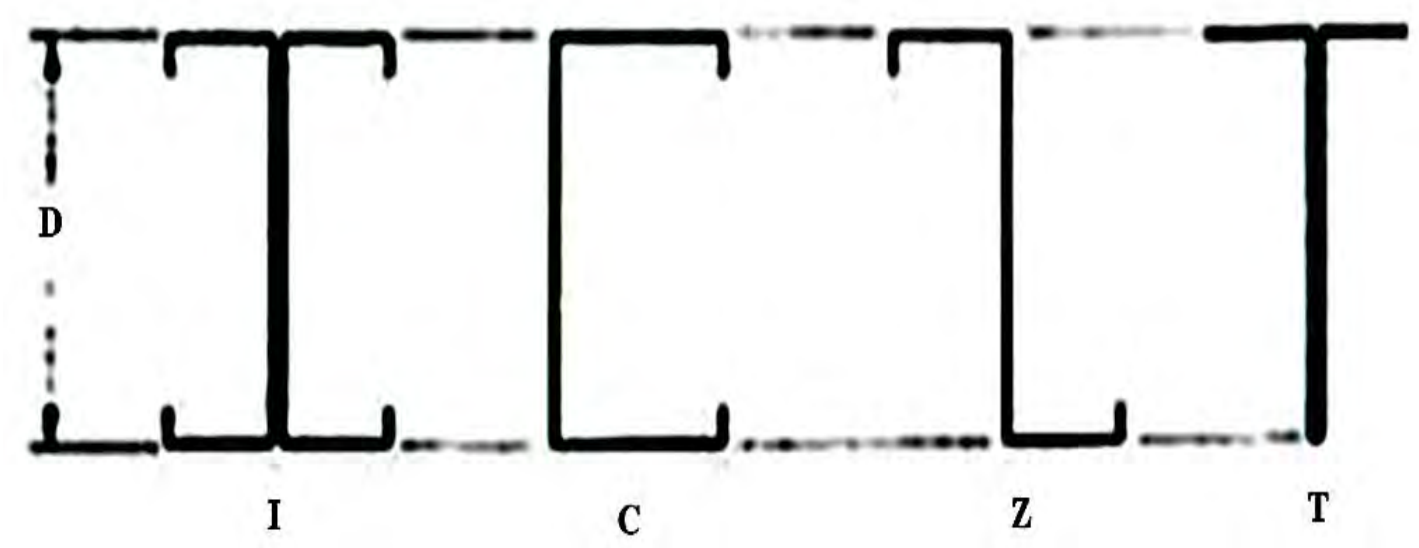

Fig .5. Cross Section covered by the Lateral buckling Clauses of BS 5950 Part 5

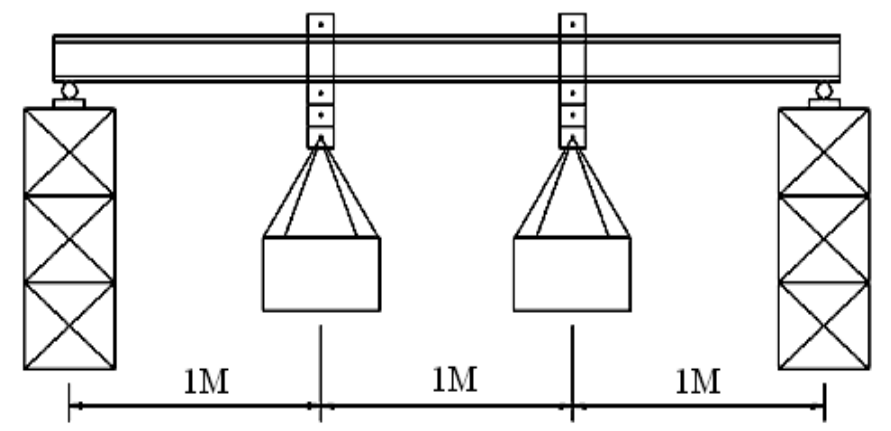

(a)

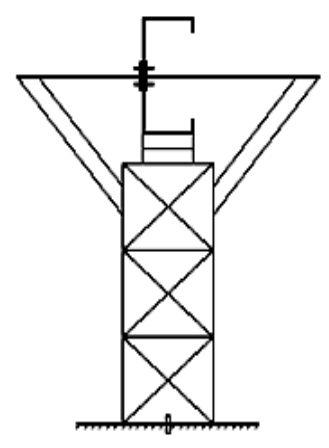

(b)

Fig .6 . Longitudinal and Side view of Test setup
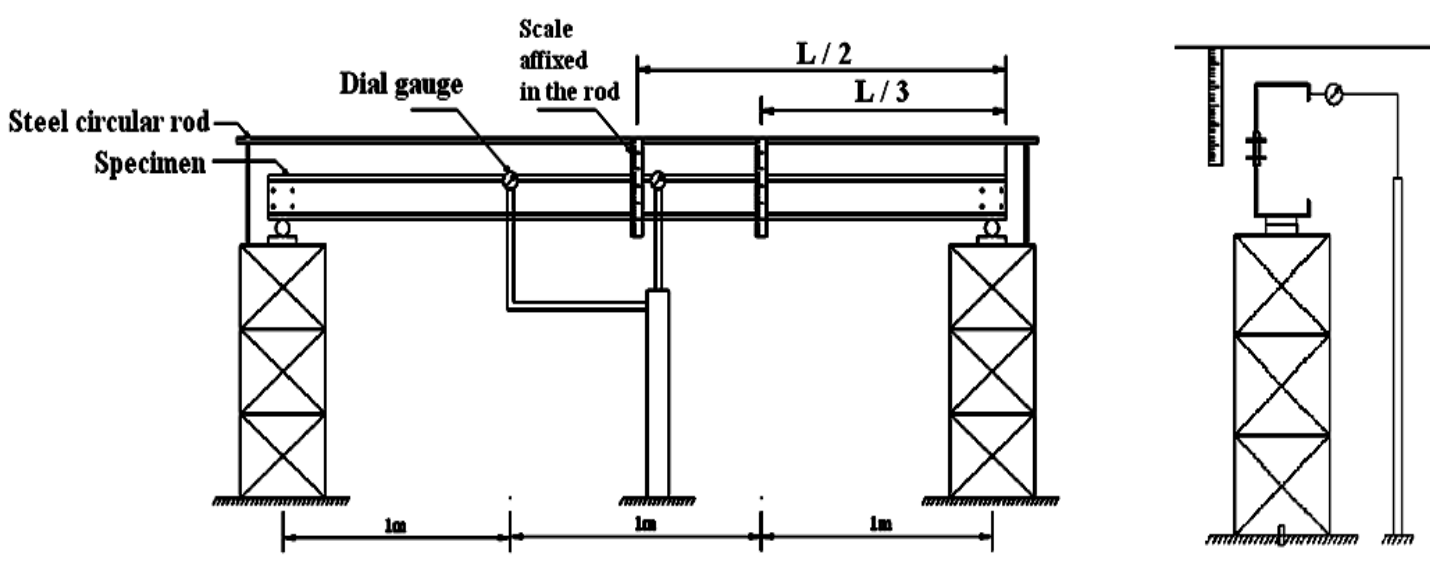

Side view 


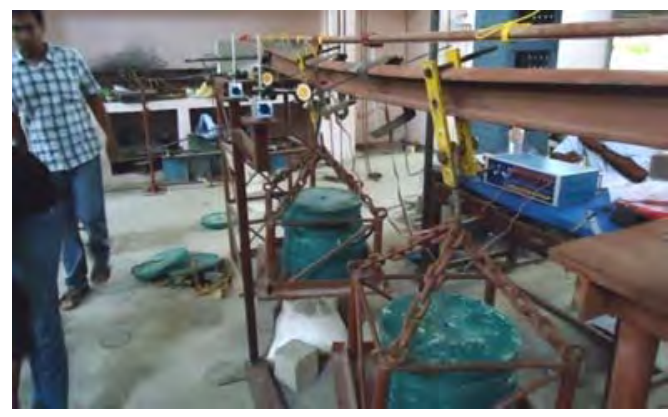

Fig.8. Test Setup
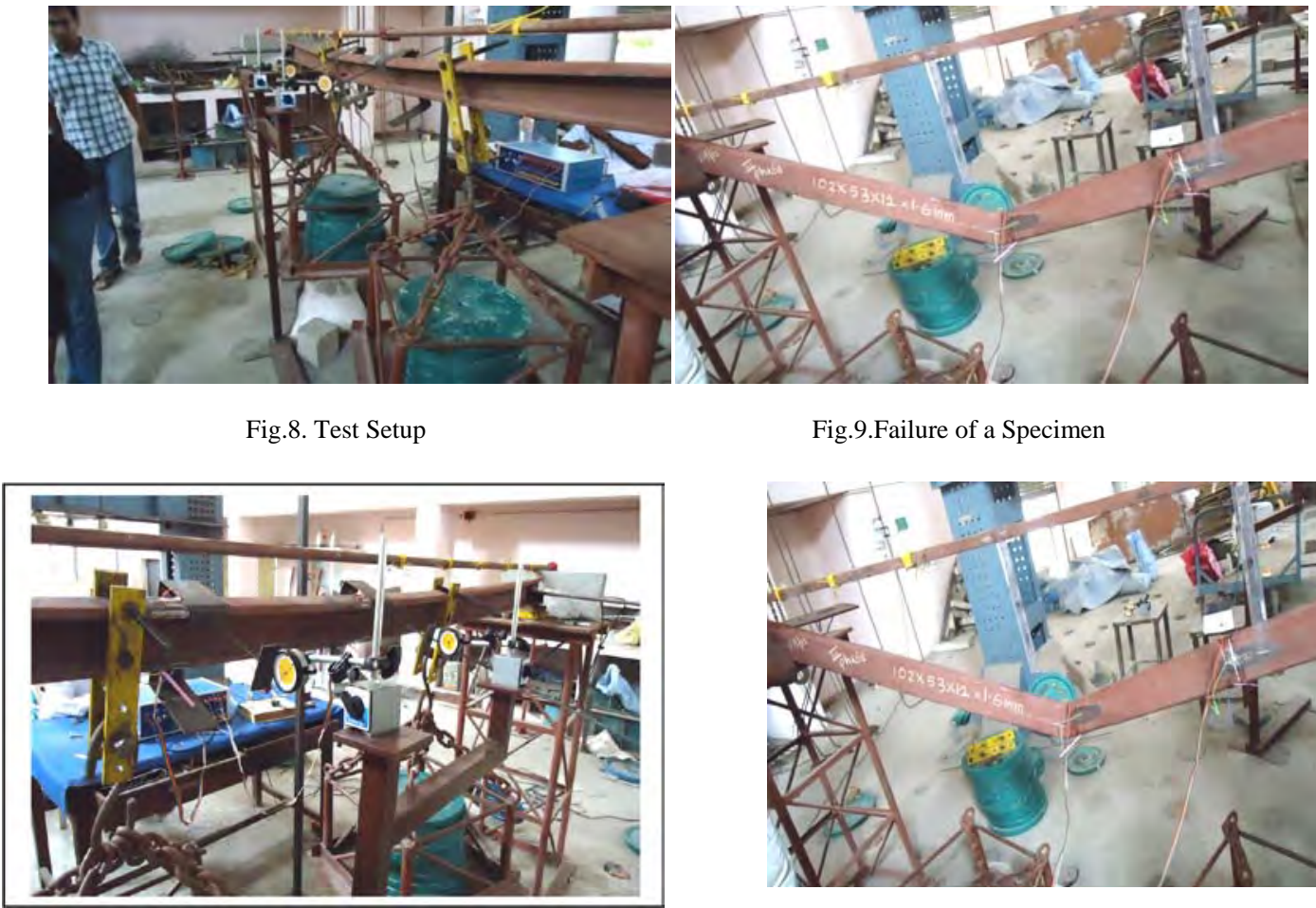

Fig.9.Failure of a Specimen

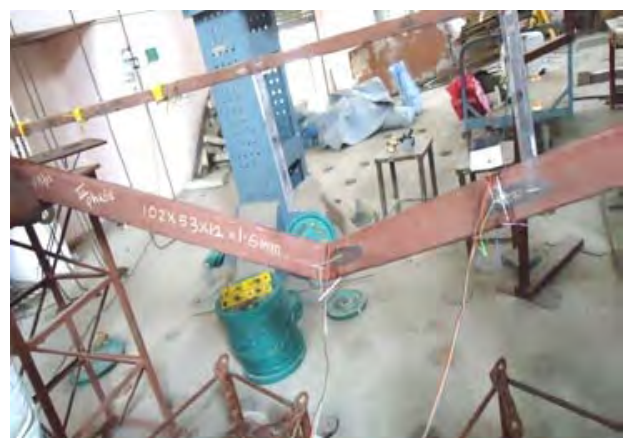

Fig.10. Loading pattern and the failure of the beam

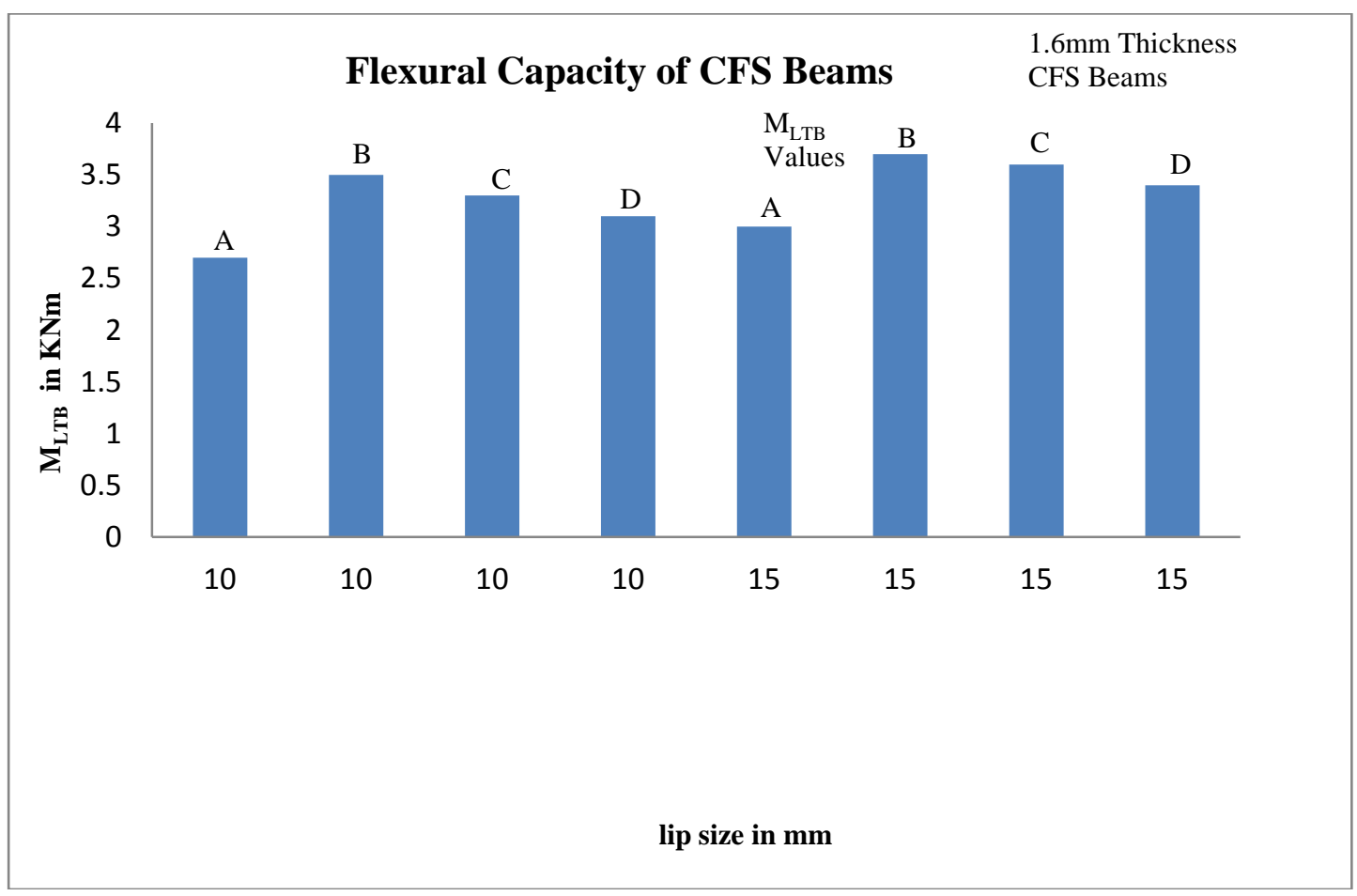

Fig .11. ( a ) 


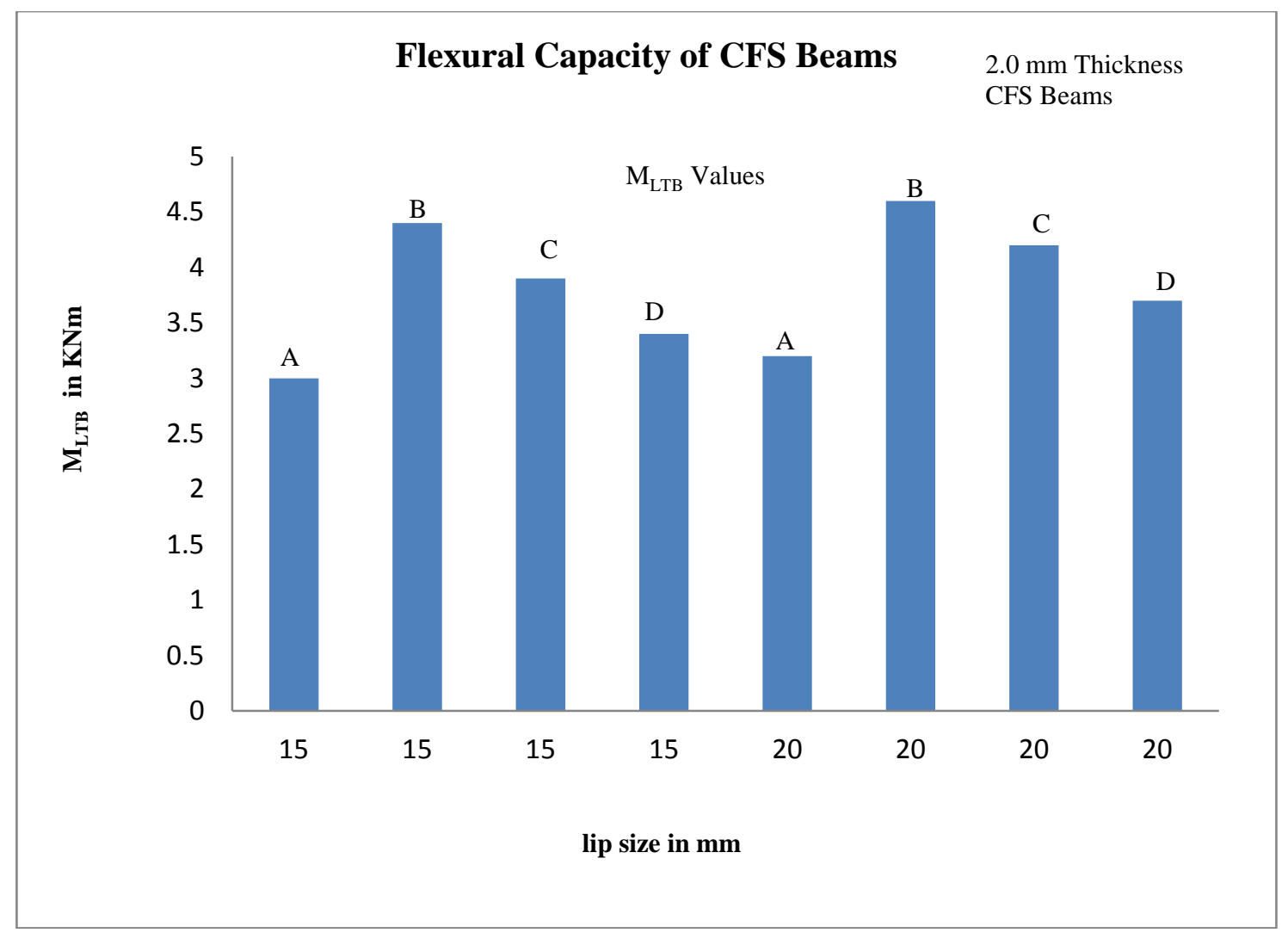

Fig. 11. (b)

Fig.11. Bar Chart showing Flexural Capacity of CFS Beams for 1.6mm and 2.0mm Thickness

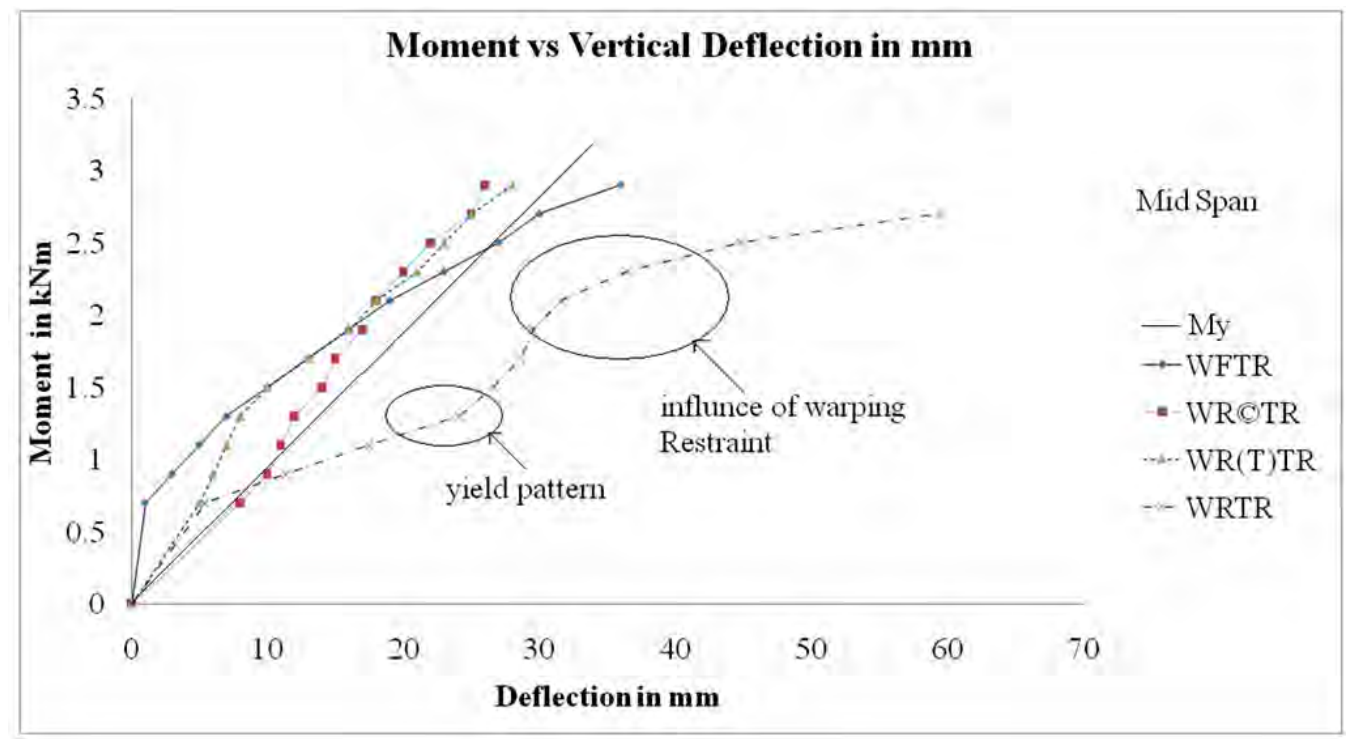

Fig. 12.(a) 


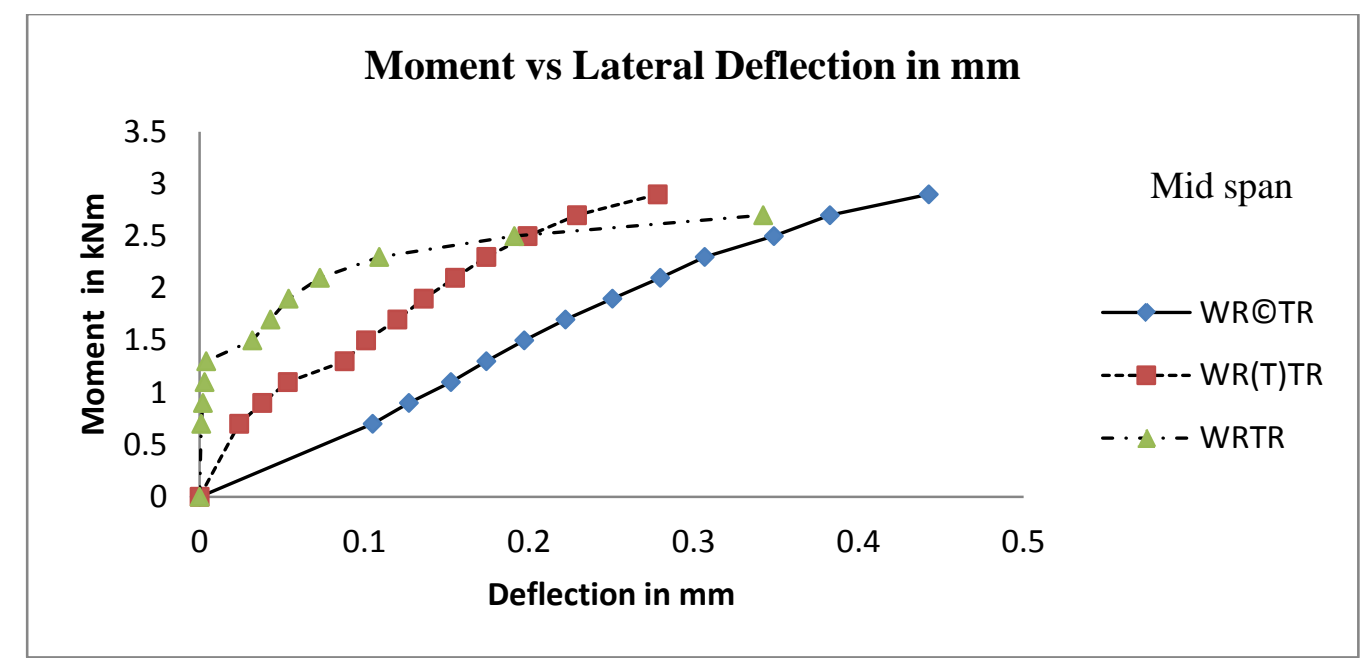

Fig .12. ( b )

Fig .12. Moment Deflection Curves

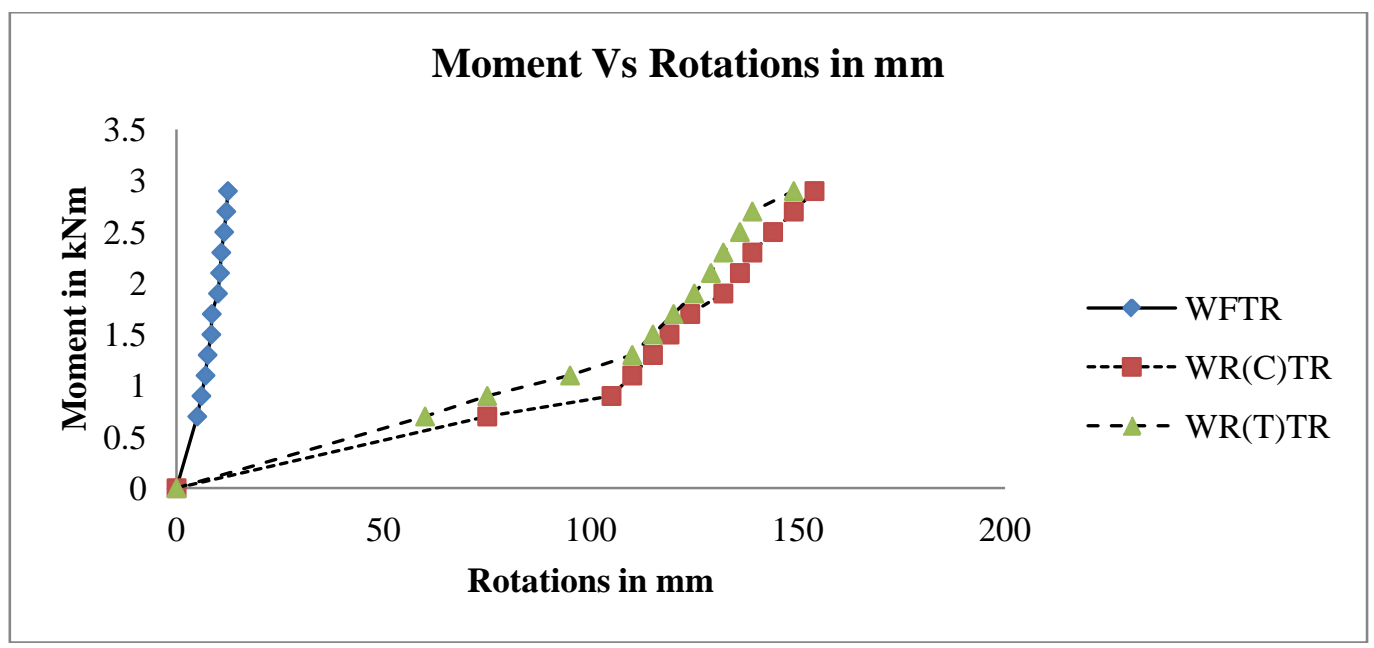

Fig.13. Moment Strain Curves 